University of South Florida

DIGITAL COMMONS Digital Commons @ University of @ UNIVERSITY OF SOUTH FLORIDA South Florida

\title{
Guidebook on Using American Community Survey Data for Transit Planning
}

CUTR

Follow this and additional works at: https://digitalcommons.usf.edu/cutr_nctr

\section{Recommended Citation}

"Guidebook on Using American Community Survey Data for Transit Planning," National Center for Transit Research (NCTR) Report No. CUTR-NCTR-RR-2008-01, Center for Urban Transportation Research, University of South Florida, 2010.

DOI: https://doi.org/10.5038/CUTR-NCTR-RR-2008-01

Available at: https://scholarcommons.usf.edu/cutr_nctr/38

This Technical Report is brought to you for free and open access by the National Center for Transit Research (NCTR) Archive (2000-2020) at Digital Commons @ University of South Florida. It has been accepted for inclusion in Research Reports by an authorized administrator of Digital Commons @ University of South Florida. For more information, please contact digitalcommons@usf.edu. 


\title{
The ACS Statistical Analyzer
}

\author{
National Center for Transit Research \\ University of South Forida, Tampa \\ March 2010
}

Final Report

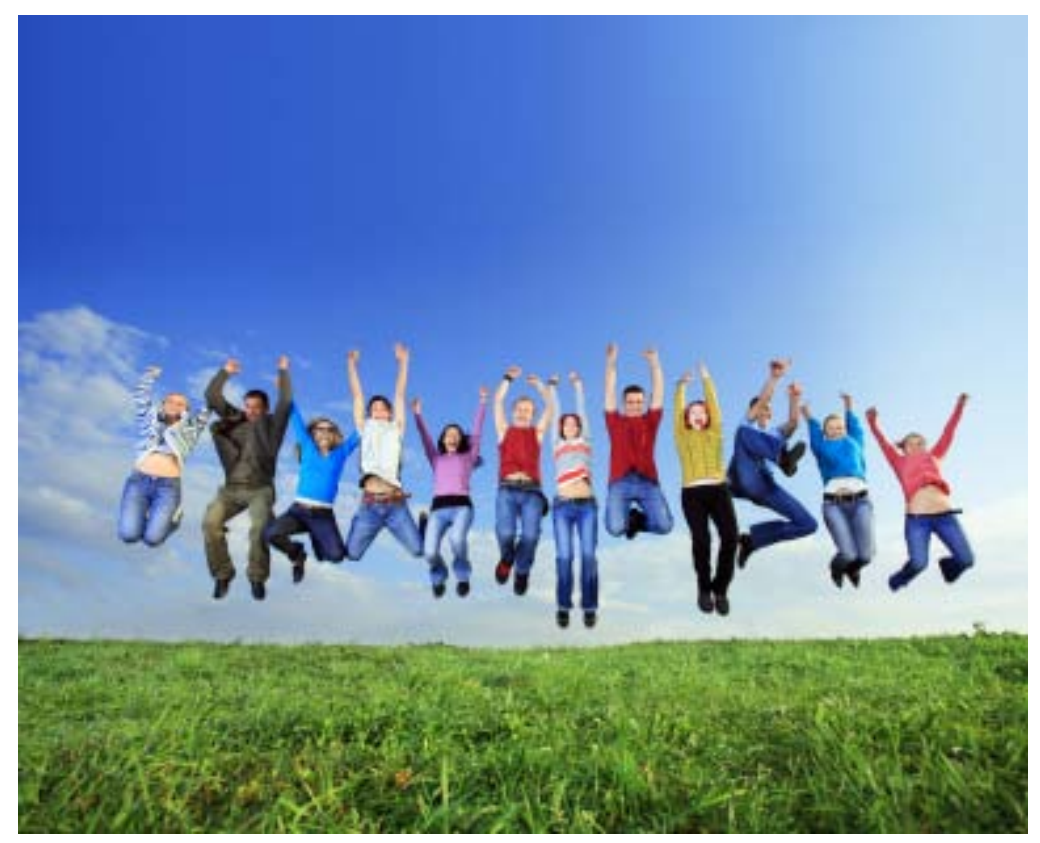

http://ebr.eller.arizona.edu/images/Oct09_photos/crowd_umping.jpg

Contract Number: BDK85 977-02 


\section{TECHNICAL REPORTDOCUMETATION PAGE}

\begin{tabular}{|c|c|c|c|}
\hline 1. Report No. & 2. Government Accession No. & 3. Recipient's Cat & \\
\hline \multirow{2}{*}{\multicolumn{2}{|c|}{$\begin{array}{l}\text { 4. Title and Subtitle } \\
\text { The ACS Statistical Analyzer }\end{array}$}} & \multicolumn{2}{|c|}{$\begin{array}{l}\text { 5. Report Date } \\
\text { March } 2010\end{array}$} \\
\hline & & \multicolumn{2}{|c|}{ 6. Performing Organization Code } \\
\hline \multicolumn{2}{|l|}{$\begin{array}{l}\text { 7. Author(s) } \\
\text { Xuehao Chu }\end{array}$} & \multicolumn{2}{|c|}{$\begin{array}{l}\text { 8. Performing Organization Report No. } \\
\text { NCTR778-02, } \\
\text { FDOT BDK85 977-02 }\end{array}$} \\
\hline \multirow{2}{*}{\multicolumn{2}{|c|}{$\begin{array}{l}\text { 9. Performing Organization Name and Address } \\
\text { National Center for Transit Research (NCTR) } \\
\text { University of South Florida } \\
4202 \text { E Fowler Ave., CUT100, Tampa, FL 33620-5375 }\end{array}$}} & \multicolumn{2}{|l|}{ 10. Work Unit No. } \\
\hline & & \multicolumn{2}{|c|}{$\begin{array}{l}\text { 11. Contract or Grant No. } \\
\text { USDOT DTRS98-G-0032 }\end{array}$} \\
\hline \multirow{3}{*}{\multicolumn{2}{|c|}{$\begin{array}{l}\text { 12. Sponsoring Agency Name and Address } \\
\text { Office of Research and Special Programs } \\
\text { U.S. Department of Transportation, Washington, D.C. } 20590 \\
\text { Florida Department of Transportation } \\
605 \text { Suwannee Street, MS 30, Tallahassee, FL } 32399\end{array}$}} & \multirow{2}{*}{\multicolumn{2}{|c|}{ 13. Type of Report and Period Covered }} \\
\hline & & & \\
\hline & & \multicolumn{2}{|c|}{ 14. Sponsoring Agency Code } \\
\hline \multicolumn{4}{|c|}{$\begin{array}{l}\text { 15. Supplementary Notes } \\
\text { Supported by a grant from the Florida Department of Transportation and the U.S. Department of } \\
\text { Transportation }\end{array}$} \\
\hline \multicolumn{4}{|c|}{$\begin{array}{l}\text { 16. Abstract } \\
\text { This document provides guidance for using the ACS Statistical Analyzer. It is an Excel-based template } \\
\text { for users of estimates from the American Community Survey (ACS) to assess the precision of individual } \\
\text { estimates and to compare pairs of estimates for their statistical differences. The ACS Statistical Analyzer } \\
\text { covers the following four functions and fifteen sub-functions (not listed): } \\
\text { - To derive other precision measures for published ACS estimates at American FactFinder or from the } \\
\text { Census Transportation Planning Products (CTPP), which already have a margin of error (MOE). } \\
\text { - To derive the precision measures for estimates that do not already have an MOE. } \\
\text { - To derive the precision measures of new estimates obtained from two or more original estimates that } \\
\text { already have an MOE. } \\
\text { - To compare pairs of two estimates that already have an MOE. } \\
\text { Measures of precision for an estimate include its MOE, relative reliability, and confidence interval. The } \\
\text { implementation of the ACS Statistical Analyzer is expected to reduce the agency cost of, and to lessen } \\
\text { the technical barriers to, dealing with the precision of ACS estimates when agencies use these estimates. } \\
\text { These direct benefits in turn can lead to wider and more effective usage of ACS data. }\end{array}$} \\
\hline $\begin{array}{l}\text { 17. Key Words } \\
\text { ACS, Census 2000, Estimates, } \\
\text { Precision, ACS Statistical } \\
\text { Analyzer, Averages, Medians, } \\
\text { Ratios, Percentages, } \\
\text { Frequencies, Totals }\end{array}$ & \multicolumn{3}{|c|}{$\begin{array}{l}\text { 18. Distribution Statement } \\
\text { Available to the public through the National Technical Information } \\
\text { Service (NTIS), } 5285 \text { Port Royal Road, Springfield, VA 22161, 703- } \\
\text { 487-465, and through the NCTR website at http://www.nctr.usf.edu }\end{array}$} \\
\hline $\begin{array}{l}\text { 19. Security Classif. (of this report) } \\
\text { Unclassified }\end{array}$ & $\begin{array}{l}\text { 20. Security Classif. (of this page) } \\
\text { Unclassified }\end{array}$ & $\begin{array}{l}\text { 21. No. of pages } \\
32\end{array}$ & 22. Price \\
\hline
\end{tabular}




\section{DISC LAIMER}

The opinions, findings, and conclusions expressed in this public ation are those of the authors and not necessa rily those of the State of Florida Department of Transportation or the U.S. Department of Transportation.

The report wasprepared in cooperation with the State of Florida Department of Transportation and the U.S. Department of Transportation. 


\section{ACKNOWFDGMENT}

The ACS Statistic al Ana lyzer was inspired by the Statistic al Signific ance Calculator (http://www.trbcensus.com/notes/Statistic alCalcula tionsMenu.xls), which was developed by the staff of the New York State Data Center at Empire State Development. The author wants to thank Patria Ball, Ed Hillsman, Steve Polzin, and J oel Volinski of the Center for Urban Transportation Research, Liang Long of Cambridge Systematics, Inc., and Mic hael Sta rsinic of the U.S. Census Bureau for their comments. These reviews do not represent an official a pproval by these organizations or their staff of the fomulas in the ACS Statistical Analyzer, the accompanying documentation, or the results obta ined by users from the ACSStatistical Analyzer. All remaining errors and shortcomings a re the author's responsibility. 


\section{Exec utive Summary}

\section{Background}

Transportation planning in general and transit planning in particular in Florida and throughout the nation have relied heavily on the commuting and socio-demographic data from the longform survey of the decennial census at various levels of geography. While the short-form count will continue every 10 years, the long-form survey has been replaced by the American Community Survey (ACS). While providing more current information, ACS data represent serious challenges for transportation planning professionals to use them effectively. One of these challenges results from the fact that the precision of estima tes from the ACS is signific a ntly lower than the precision of estimates from the traditional dec ennial c ensus long-form survey. This requires transportation planning professiona ls to explic itly take into account the precision of estima tes from the ACS when they use these estimates either individually or for compa risons. Transportation planning professionals, however, face diffic ulties in overcoming this challenge:

- Estimates in published ACS tables at Americ an FactFinder come with a marg in of error (MOE) but without other mea sures of prec ision. This makes it diffic ult for tra nsportation planning professionals to judge the usability of these estimates.

- Some estimates do not come with any measure of precision. While necessary sta tistical procedures and formulas a re available in various doc uments from the U.S. Census Bureau, they are not easily accessible to many transportation planning professionals.

- When the procedures and fomulas a re accessible, they typically involve statistical procedures and formulas that many transportation planning professionals do not feel comfortable working with.

\section{Objectives}

The objective of this project was to develop a tool that helps transportation planning professionals overcome these diffic ulties in using ACS data. The target users a re those who are familiar with the statistical concepts involved, a re familia $r$ with the mea sures of precision and their use, and a re even capable of following the statistical procedures and formulas, but do not want to go through these proceduresand fomulas by themselves.

\section{Findings and Conclusions}

The resulting tool from the resea rch project is the ACS Statistic al Analyzer. Transportation planning professionals can use it to assess the precision of individual estimates in tems of several measures of precision without the need to work directly with the statistic al procedures and formulas involved. They also can use this tool to compare pairs of estimates in tems of their statistical differences without the need to work directly with the statistic al procedures and fo mulas involved. The tool is comprehensive and covers a full range of functions and subfunctions for transportation planning professionals to derive measures of precision in individual estima tes and to compare estimates: 
A. To derive other precision mea sures for published ACS estimates at Americ an FactFinder or estimates in the Census Transportation Planning Products (CTPP) for ACS data. Estimates from these two sources come with a margin of error (MOE):

01. For up to $200 \mathrm{ACS}$ estimates from the same table.

B. To derive the precision mea sures for individual estima tes that do not alrea dy have an MOE. These include published Census 2000 estimates, C TPP 2000 estimates, ind ividual user-derived estima tes from an ACS Public Use Mic roda ta Sample (PUMS), and user-derived estimates from a Census 2000 PUMS.

02. For frequencies, totals, a verages, or medians from an ACS PUMS using replic ate estimates.

03. For a verages from Census 2000 or a PUMS using a distribution ta ble.

04. For medians from Census 2000 or a PUMS using a distribution table.

05. For frequencies from Census 2000 or a PUMS using design factors.

06. For percentages from 2000 Census or a PUMS using design factors.

C. To derive the precision measures for new estimates obta ined from two or more original estimates that a lready have an MOE. These estimates can be published ACS estimates, CTPP estimates, estimates whose precision measures a re derived using Function $B$, or estimates whose precision mea sures a re derived using a nother sub-function of this function. This function covers estimates obta ined using one of the following six operations:

07. Sum of two or more estimates.

08. Difference of two estimates.

09. Percent difference of two estimates.

10. Ratio of one estimate over a nother.

11. Percentage of one estimate in a nother.

12. Product of two estimates.

D. To compare pairs of two estimates that already have an MOE. The estimates to be compared may be published ACS estimates, CTPP estimates, estima tes whose prec ision mea sures are derived using Function B, or estimates that a re derived along with their precision mea sures using Function $C$. This func tion covers three types of comparisons:

13. One ACS estimate with a nother.

14. One ACS estimate with a Census 2000 estima te using a ctual MOE.

15. One ACS estimate with a Census 2000 estima te using assumed MOE.

\section{Benefits}

The implementation of the ACS Statistical Ana lyzer is expected to reduce agencies' cost and lessen the technical ba miers to dealing with the precision of ACS estimates when agencies use these estimates for transportation planning. These direct benefits, in tum, can lead to wider and more effective use of ACSdata for transportation planning.

This project was conducted by Xuehao Chu at the University of South Florida. For more information, contact Daniel Harris, Transit Pla nning Project Manager, at (850) 414-4532, daniel.hanis@dot.state.fl.us. 


\section{TABIF OF CONTENTS}

\section{Sections}

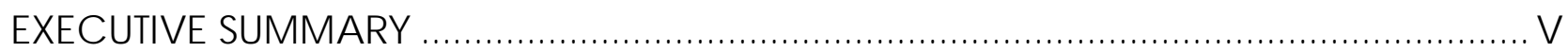

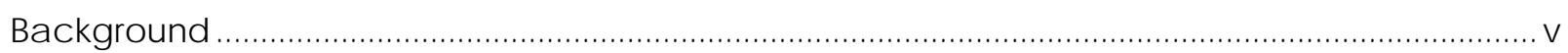

Objectives

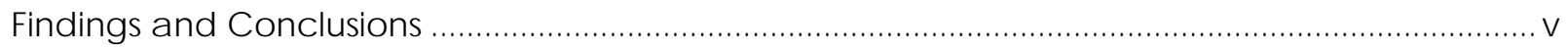

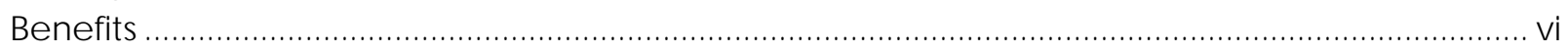

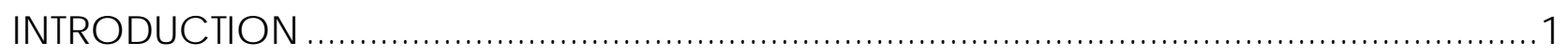

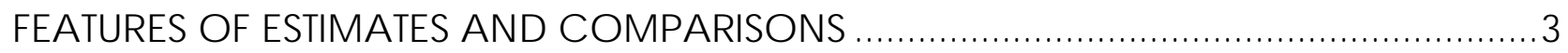

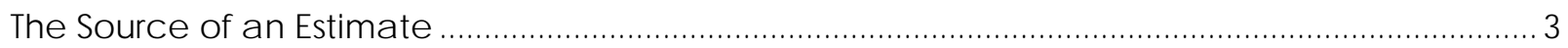

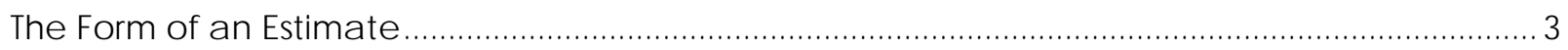

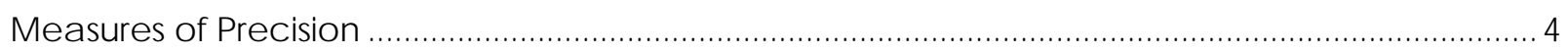

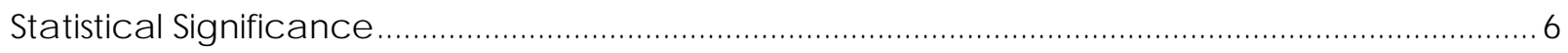

FUNC TIO NS AND SUB-FUNC TIO NS

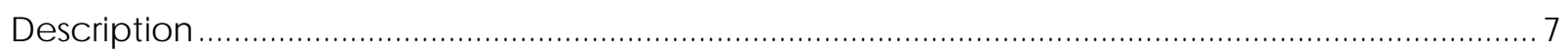

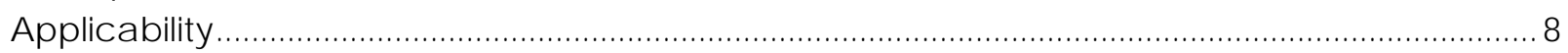

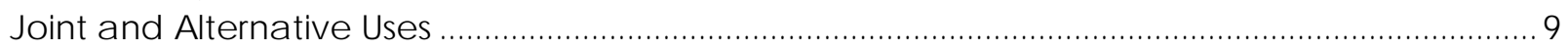

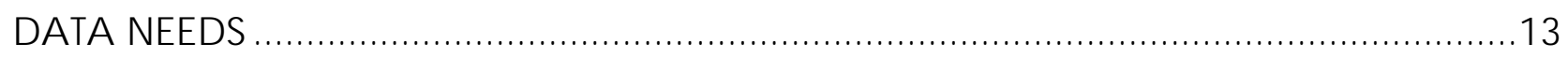

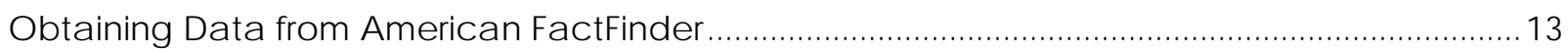

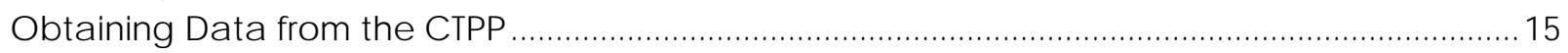

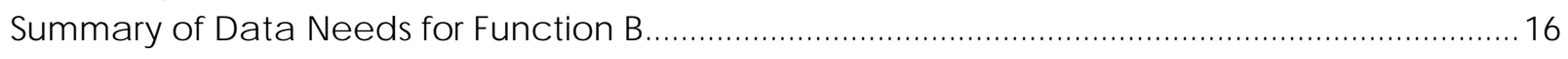

Obta ining Required Data for Function B .............................................................................. 18

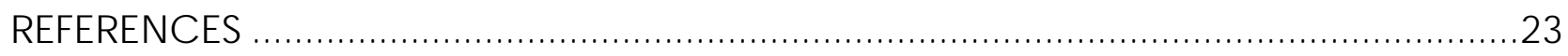

APPENDIX

\section{list of Figures}

Figure 1. U.S. Census Burea u's Web Page for Census 2000 Information ............................................ 14

Figure 2. ACSWeb Page for Available Data Sets............................................................................. 15

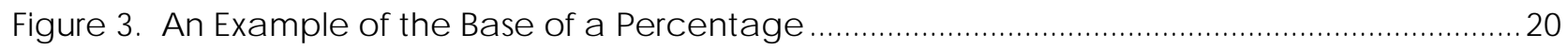

\section{List of Tables}

Table 1. Unique Data Requirements for Function B................................................................... 16

Table 2. Finite Population Correction Factor by Data Source ......................................................... 16

Table 3. American FactFinder "Detailed Tables" for Size of the Geography....................................18

Table 4. A Distribution Table of Household Income, Miami, Florida ......................................................19

Table 5. Detailed Table P31, Miami City, Florida .................................................................................21

Table 6. American FactFinder “Deta iled Tables” for Percent in Sample Values.................................21 
This page intentiona lly left blank. 


\section{INTRODUCTION}

The Americ an Community Survey (ACS) a nnually collects socio-economic and commuting data from a sample of housing units that is much smaller than the long-form survey during the decennial census. Estima tes from the ACS ma y be used ind ividually for ind ic a ting the condition of a geographic area or of a sub-population in the area. The percentage of the households under poverty would be a condition of a geographic area, while the average household income among households under poverty would be a condition of a sub-population group. Estima tes from the ACS may a lso be used jo intly for indic ating differences in the conditions of different geographic a reas or different sub-population groups or for ind ic ating changes in the condition of a given geographic a rea or for a given sub-population overtime.

Estima tes from a ll surveys include some amount of error due to sampling, and the a mount of error with estimates from the ACS is sig nific a ntly greater than that with estima tes from the tra ditional long-form survey. The U.S. Census Bureau has the following guidance to using estima tes from the ACS for both of the above purposes:

"As the ACS estimates are based on a sample survey of the U.S. population, information about the sampling emorassociated with the estimates must be taken into account when a na lyzing individual estima tes or compa ring pairs of estima tes a cross a reas, population groups, or time periods."

This ACS Statistic al Ana lyzer helps users of ACS estima tes follow this guidance of the U.S. Census Bureau. An ACS estimate can come from one of several sources. These include published ACS tables at American FactFinder, estimates from the Census Transportation Planning Products (CTPP), those derived from these published estimates or CTPP estimates, and those derived from any ACS Public Use Mic rodata Sample (PUMS).

Although the ACS Statistical Ana lyzer foc uses on ACS estimates, it a lso dea ls with Census 2000 estimates. Users of ACS estima tes often want to compare current conditions as reflected in ACS estima tes with conditions in 2000 as reflec ted in Census 2000 estima tes. Census 2000 estima tes a Iso include not only those in the published tables at Americ an FactFinder, but also those from CTPP tables, those derived from the published tables or CTPP tables, and those derived from a 2000 PUMS.

This d oc ument is a guide to using the ACSStatistical Ana lyzer. It combines the va rious piec es of the guidance to using the ACS Statistical Analyzer that is a lrea dy conta ined in the ACS Statistic al Analyzer. The remainder of this document is divided into three sections:

- Features of Estimates a nd Compa risons defines the essential features of a n estimate and a key fea ture of statistic al comparisons used throughout the ACS Statistical Ana lyzer and this d oc ument. These features include the source of an estimate, the different forms of an estimate, measures of precision for a n estimate, and sta tistic al signific a nce. 
- Functions a nd Sub-Func tions summa rizes the 4 functions and 15 sub-functions that the ACS Statistic al Analyzer serves. It a Iso disc usses the a pplic a bility of these functions and sub-functions and the joint use of more tha $n$ one sub-function for certa in a nalyses.

- Data Needs details data needs for using the ACS Statistical Analyzer a nd how the user may obta in them.

In addition, an appendix provides the statistic al procedures and formulas used for each function and sub-function for those curious users. 


\section{FATURES OF ESTIMATES AND COMPARISONS}

This chapter foc uses on describing the essential fea tures of an estimate and a comparison. The primary objective is to familiarize the user with a few basic conceptsand terms used in the ACS Statistical Analyzer and this guide. The key feature of a companison is statistical signific ance, and the essential features of an estimate are grouped into three categories:

- The source of a n estimate.

- The form of a n estimate.

- The measures of precision for an estimate.

\section{The Source of an Estimate}

The original source of a ny estima te that can be analyzed by the ACS Statistic al Analyzer is either the ACS or the Census 2000 long-form survey. The direct sourc es of estimates that can be a nalyzed with the ACS Statistical Ana lyzer are:

- ACS estimates in published tables at American FactFinder.

- Census 2000 estima tes from Summary File 3 in published ta bles at Americ an FactFinder.

- ACS estimates from the CTPP.

- Census 2000 estima tes from the CTPP.

- User-derived ACS estimates from two or more published ACS estimates.

- User-derived estima tes from two or more published Census 2000 estimates.

- User-derived estimates from two or more CTPP estimates.

- User-derived estimates from an ACSPUMS.

- User-derived estimates from a Census 2000 PUMS.

Americ an FactFinder is the web site that the U.S. Census Bureau has developed as its primary vehic le for distributing Census data, including data from Census 2000 and the ACS. The CTPP contains tables specially designed and tabulated for the transportation community. For both Census 2000 and the ACS, the CTPP conta ins three sets of tablesthat show residence characteristics, workplace characteristic s, and commuter-flow characteristic s. A PUMS is a public use microdata sample that represents a sub-sample of the Census 2000 long-form survey or the ACS. Census 2000 has two PUMS data sets representing $1 \%$ and $5 \%$ of the population. The ACS has one PUMS dataset representing approximately $1 \%$ of the population.

The user is assumed to be a ware of these sources. As a result, these sources for using the ACS Statistic al Analyzer a re not described here. Some aspects of obtaining estima tes from these sources, however, are described in the section on data needs.

\section{The Form of an Estimate}

An estimate of a characteristic of a population is a numeric al value obta ined from a statistic al sample of the population to represent the true value of the characteristic that would have been obtained from the entire population. Estimates from both the ACS and the Census 2000 longform survey a re based on interview data collected from samples of all housing units. Estima tes 
ma y take different forms, including frequencies, totals, ratios, percentages, a verages, and medians.

Frequencies. An estimate of a frequency represents the size of a population in tems of persons, households, fa milies, or housing units.

Totals. A total represents the total a mount of some characteristic of a population. The U.S. Census Bureau uses the word "aggregate" to describe a total. Examples include household inc ome, vehic les a vailable, rent paid, wage eamings, commuting time, etc.

Ratios. A ratio is one estima te (i.e., the numerator) divided by a nother estima te (i.e., the denominator), with the numerator not being part of the denominator. The average number of workers per household is one example where the numerator is the total number of workers and the denominator is the total number of households in a geographic area. The number of workers who commute to work by public transportation divided by the total number of workers would not be a ratio because the numerator, in this case, is part of the denominator.

Percentages. A percentage is a ratio multiplied by 100 with the numerator being part of the denominator. One example would be the percentage of workers who usually commute to work by public transportation.

The ACS Sta tistic al Ana lyzer disting uishes two types of percenta ges: frequency-based and total-based. A frequency-based percentage uses frequencies for their numerator and denominator. The percentage of workers who usually commute to work by a particular mode is an example of a frequency-based percentage. A total-based percentage, on the other hand, uses totals for the numerator and denominator. Consider vehic les a vaila ble in households. The percentage of vehicles available in households under poverty versus vehic les a vailable in all households is a n example of total-based percentages.

Averages. An average may be estimated as the ratio between an estimate of a total as the numerator and an estimate of a frequency as the denominator. The average commute time per worker is a n example where the total is the total a mount of commuting time for a sub-population in a geographic area and the frequency is the total number of workersfor the same sub-population and geographic area.

Medians. The median divides the total population into two equal parts: one-ha If of the cases fall below the median and one-half of the cases exceed the median. One example would be median household income.

The ACS Sta tistic al Ana lyzer distinguishes these different forms of an estimate bec a use the statistical proceduresand formula sfor deriving measures of precision differ for these different forms of estimates.

\section{Measures of Precision}

The ACS Statistic al Ana lyzer foc uses on three mea sures of prec ision, inc lud ing rela tive reliability, confidence interval, and margin of emor. Although it is not directly used in the ACS Statistic al Analyzer, the concept of standard emor is described first because it is the centerpiece to all 
three mea sures of precision. In addition, standard emror and relative relia bility are features of the estimates, but confidence interval and margin of emor also depend on the so-called level of confidence.

Standard Enor. There are many possible samples that could be observed from a given population. In practice, we observe only one of these samples, and one estimate of the true value is produced from that sample. Consider the average of estimates from all possible samples from the same population. The standard emor is an estimate of how much the possible estimates from these many possible samples differ from their a verage. Smaller standard errors suggest that the many possible estimates, including the one for the observed sample, tend to be close to each other.

Relative Reliability. The standard error of an estimate gives an absolute measure of the estimate's precision. A relative measure of precision, however, often is more effective in determining the usability of an estimate. The relative reliability of an estimate is the ratio of its standard error to the estimate, expressed in tems of a percentage. The lower the ratio, the higher the relative reliability of the estimate.

In "ACSAdvanced Applications and Issues: Technical Append ix to ACS User Handbook, unpublished draft," Leonard Gaines has suggested the following criteria in using rela tive reliability to determine the usa bility of an estima te:

- In many applications, a level of rela tive relia bility of $10 \%$ or less is desira ble.

- The user should be cautious before using estimates with a level of rela tive reliability greater than $10 \%$ but not greater than $50 \%$.

- Avoid using estima tes with a relative reliability level grea ter than $50 \%$.

These criteria may be used not only to determine the usa bility of individual estimates, but also to increase the precision in estimatesused in a pplications, especially for ACS data. The precision of ACS data can be improved by using estimates for a longer period or by aggregating across geographic areasand population groups. If the estimate of interest is for a specific geographic a rea and a specific population group, multiyear estimates should be used where possible when the single-year estimate hasa level of relative reliability that is greater than $10 \%$

Level of Confidence. A level of confidence shows how likely a finding is due to chance. The most commonly used level is $95 \%$. This means that a finding hasa $95 \%$ chance of being true. A level of confidence is used in constructing a confidence interval and a margin of error, and in detemining whether the difference between two estimates is statistic a lly signific ant.

Confidence Interval. An estimate and its standard error permit the construction of a confidence interval that represents the degree of precision about the estimate at a partic ula r level of confidence. A confidence interval consists of a lower bound and an upper bound. The center of the interval is the estimate, and both the standard error and the level of confidence determine the two bounds. The level of confidence plays a role in determining the two bounds through a confidence multiplier. This multiplier is $1.645,1.96$, 
and 2.576 for confidence levels of $90 \%, 95 \%$, and $99 \%$, respectively. Specific ally, the lower and upper bounds of a $90 \%$ c onfidence interval for an estimate are:

$$
\begin{aligned}
& \text { Lower bound =estimate }-1.645 * \text { standard error. } \\
& \text { Upper bound }=\text { estimate }-1.645 * \text { standard error. }
\end{aligned}
$$

Over all possible samples of a population, $90 \%$ of the intervals produced in this way conta in the true value.

Margin of Error. The standard error of an estimate can be used to construct the margin of error at a specific level of confidence. It is one-ha If of the width of a $90 \%$ confidence interval of the estimate for the cases where the confidence interval is symmetric a round the estimate. Specific ally, the margin of emror at the $90 \%$ confidence level is given by $1.645 *$ standard error.

\section{Statistical Significance}

The concept of statistical significance is used in determining whether the difference between two estimates is not likely to be from random chance alone. This determination is based on the two estimates, their mea sures of precision, and a desired confidence level. Two estima tes found to be significantly different at the $90 \%$ confidence level means that one can be $90 \%$ certa in that the difference truly exists or that there is a less than $10 \%$ chance that the difference came entirely from random chance.

It is important for users to be a wa re of several issues with the concept of statistic al significance:

- In non-statistical terms, being signific a nt often mea ns being important. In statistic al terms, however, being statistic ally signific ant means being probably true (not due to chance). For a difference being important requires the magnitude of the difference being large enough. Userscan use the ACS Statistical Analyzer to determine if the difference between two estima tes is sta tistic ally signific ant, but users need to determine if the difference is important outside the ACS Statistical Ana lyzer.

- If many comparisons are done, fa lsely significant results a re a problem. A 95\%chance of something being true means that there is a $5 \%$ chance of it being false. This means that of every 100 comparisons that show results signific ant at the $95 \%$ level, the odds a re that 5 of them do so falsely. If you took a totally random, mea ningless set of data and did 100 tests of signific ance, the odds a re that 5 tests would be falsely reported to be significant.

- If the impact of an incorrect conclusion reached from a comparison is substantial, the user should consider increasing the level of confidence for the comparison.

- Fa iling to find evidence that there is a statistic a lly signific a nt difference between two estima tes does not constitute evidence that there is no difference between them. 


\section{FUNCTIONS AND SUB-FUNCTIONS}

This section describes the individual functions a nd sub-functions of the ACS Statistical Ana lyzer, disc usses their a pplic ability, and presents several exa mples of their jo int and altemative uses.

\section{Description}

The ACS Sta tistic al Ana lyzer serves 4 functions (A, B, C , D) and 15 sub-functions:

A. To derive other precision mea sures for ACS estimates in published tables at Americ an FactFinder or estimates in CTPP ACS tables. Estima tes from these two sourc es come with a marg in of error (MOE):

01. For up to 200 AC Sestimates from the sa me table (A01-ACS).

B. To derive the precision mea sures for individual estimates that do not alrea dy have an MOE. These include published Census 2000 estimates, C TPP 2000 estimates, ind ividual user-d erived estima tes from an ACS PUMS, and user-derived estimates from a Census 2000 PUMS.

02. For frequencies, totals, a verages, or medians from an ACSPUMS using replic a te estima tes (B02-ACS Direct).

03. For averages from Census 2000 or a PUMS using a distribution ta ble (B03-Average).

04. For medians from Census 2000 or a PUMS using a distribution ta ble (B04-Median).

05. For frequencies from Census 2000 or a PUMS using design factors (B05-Frequency).

06. For perc entages from 2000 Census or a PUMS using design factors (B06-Percentage).

C. To derive the precision measures for new estimates obta ined from two or more original estima tes that a lrea dy have an MOE. These estima tes can be published ACS estimates, C TPP estimates, estimates whose precision mea sures are derived using Function $B$, or estimates whose precision measures a re derived using a nother sub-function of this function. This function covers estimates obta ined using one of the following six operations:

07. Sum of two or more estimates (C07-Sum).

08. Difference of two estimates (C08-Diff).

09. Percent difference of two estimates (C09-\%Diff).

10. Ratio of one estima te over a nother (C10-Ratio).

11. Percentage of one estimate in a nother (C11-Percentage).

12. Product of two estimates (C12-Product).

D. To compare pairs of two estimates that already have an MOE. The estimates to be compared may be published ACS estimates, CTPP ACS estimates, estima tes whose precision mea sures are derived using Function B, or estimates that a re derived along with their precision mea sures using Function $C$. This func tion covers three types of comparisons:

13. One ACS estima te with a nother (D13-AC S\&ACS).

14. One ACS estimate with a Census 2000 estima te using an actual MOE for the 2000 estima te (D14-ACS82000 Actual). 
15. One ACS estimate with a Census 2000 estima te using an a ssumed MOE for the 2000 estima te (D15-AC \$82000 Assumed)

\section{Applicability}

The applic ability of a function or sub-function refers to the conditions under which it may be used or the conditions under which it must not be used. There a re two types of conditions that determine the applic ability of these functions and sub-functions. One type has to do with the design of the template. The other type is statistical in nature and has to do with the applicability of the statistic al proc edures and formula involved. Both of these conditions a re explic itly stated in the worksheet for each sub-function. The design-related conditions a re straightforward and are not repeated here. The statistic al conditions require some disc ussion here.

\section{Place of Work Characteristics}

Users of the ACS Statistical Ana lyzer must not use sub-func tions B03 - B06 to derive mea sures of prec ision for estimates of place of work characteristic s for Census 2000, inc lud ing published estima tes at Americ an Fa c tFinder, CTPP estimates, or user-derived estima tes from a PUMS. Data on place of work in both ACS and Census 2000 refer to the cha racteristic s of workers that a re tabulated for the geographic location at which these workers ca mied out their occupational activities during the week prior to the date of data collection. Data for the ACS and the Census 2000 long-form survey were collected with sampling done in terms of residences. As a result, c erta in nec essary input data required for some of the sub-functions for deriving mea sures of precision a re available for residential places but not a vailable for work places.

However, sub-function B02 - ACS Directcan be used to derive measures of prec ision for estima tes of place of work charac teristic s using replace weights from an ACS PUMS.

\section{Measures of Prec ision for Totals and Total-Based Percentages}

Users must not use sub-function B05 - Frequency to derive mea sures of precision for estima tes of tota ls such as total household inc ome, total commuting time by workers, total number of vehic les a va ilable, total rent, etc. in a geographic a rea. This sub-function a pplies only to estima tes of frequenc ies such as the number of persons, households, families, or housing units. Refer to the next sub-section on joint and a Itemative uses of the ACS Statistic al Analyzer for suggestions on deriving mea sures of precision for estimates of totals.

Users must not use sub-function B06 - Percentage to derive mea sures of precision for estimates of total-based percentages. The percentage of vehic les a vailable in households under poverty versus vehic les a vailable in all households in an a rea would be an example of total-related percentages. This sub-function a p plies only to estima tes of frequency-ba sed percentages. The percentage of workers who usually commuted to work by bus in a state would be an example of frequency-related percentages. Refer to the next sub-section on joint and altemative uses of the ACS Statistic al Analyzer for suggestions on deriving measures of prec ision for estima tes of total-related percentages. 


\section{Comparing ACS Estimates}

Sub-function D13 - AC SSACS can be used to compare ACS estimates, but it must not be used for comparing ACS estima tes that overla $\mathrm{p}$. For comparing estimates from single-year data, the two a reasbeing compared must not overlap if the comparison is between two areas (i.e., they do not share a common area). In addition, the two population groups must not overlap if the comparison is between two population groups (i.e., they do not include a common group).

For multi-yea r estimates, a void compa ring them with single-yea r estimates(e.g., three-year vs. one-year); a void comparing two multi-year periods of different lengths (e.g., three-year vs. fiveyear); avoid comparing one pre-2006 and one post-2006 (inclusive of 2006) period for an a rea with a substantial group quarters population; and avoid comparing two multi-yearperiods that overlap (e.g., 2005-2009 vs. 2006-2010).

\section{Comparing ACS and 2000 Estimates}

Sub-Functions D14 - AC \$\$2000 Actual and D15 - AC S\$2000 Assumed can be used to compare ACS and Census 2000 estimates, but must not be used to compare estimates between the ACS and Census 2000 that may be affected by these key differences between AC Sand 2000 data: 1) residence rules (usual residence for Census 2000 but two-month residence for the ACS); 2) reference period (prior calendar year for Census 2000 but prior 12 months for the ACSfor income and school attendance); and 3) sea sonal va riation (April 1 for Census 2000 but continuous for the ACS).

\section{J oint and Altemative Uses}

For some sta tistic al a na lyses of ACS or 2000 estimates, users need to use more than one subfunction. Such joint use of sub-functions can occur both for comparing estimates and for deriving measures of precision for individual estimates. In addition, sub-functions can be used for a ltema tive purposes other tha $n$ their original design purposes. These joint and a ltema tive uses of the sub-functions increa se the flexibility of the ACS Statistic al Ana lyzer flexible for its users.

\section{Joint Use}

\section{Comparing Estimates}

In many cases, users may get two ACS estimates and their MOE directly from Americ an FactFinder or the CTPP and conduct a statistical test to determine whether these two estimates are statistic ally different at a desired level of confidence. In many other cases, however, one or both estima tes to be compared and their measures of precision may be derived from using one of the other sub-functions before Function $D$ is used for the comparison.

\section{Deriving Measures of Precision}

Three joint uses of more than one sub-function are disc ussed for deriving mea sures of precision: 
1. For certa in forms of estimates, users may need to use more than one sub-function to derive their mea sures of precision. For example, users would need to use two sub-functions in two sequential steps to derive mea sures of prec ision for estima tes of ratios:

- If the estimates a re from published Census 2000 ta bles or a Census 2000 PUMS, these two steps a re:

1) Estimating the numerator and denominator sepa rately and their mea sures of precision using one of the last four sub-functions of Function B. The particular subfunction to use depends on the form of the estimates, including averages, medians, frequencies, or percentages.

2) Deriving mea sures of precision for the ratios using the results from the first step and sub-func tion C 10 - Ratio.

- If the estimatesare from an ACS PUMS, the second step would rema in the same, but the first step would be to estima te the numerator and denominator separately and to derive their mea sures of prec ision using sub-function B02 - ACS Direct or one of the subfunc tions of Function B for frequencies, averages, or medians.

2. Deriving measures of precision for estimates of totals, such as total household inc ome for a sub-population in a geographic area, would involve using three sub-functions sequentially:

1) Using sub-function B03 - Average to derive measures of precision for both the relevant a verage. For an estimate of total household inc ome for a sub-population in an a rea, for example, the average would be household income perhousehold in the sub-population, and the total frequency would be the total number of households in the sub-population of the area.

2) Using B05 - Frequency to derive measures of precision for the total frequency. In the example of household income, the total frequency would be the number of households in the sub-population.

3) Using sub-function $\mathbf{C 1 2}$ - Product to derive the measures of precision for the estimate of a total. The two estimates for the product are the average and the total frequency.

3. Deriving measures of precision for estimates of total-related percentages would involve using four sub-functions sequentially. Consider the percentage of vehic les a va ila ble in households under poverty versus vehic les a vaila ble in all households a s a n example:

1) Using sub-function B03 - Average to derive measures of precision for the relevant average. This step needs to be done for the average vehicles available per household for households under poverty and for all households, respectively.

2) Using B05 - Frequency to derive measures of precision for the total frequency. This step needs to be done both for the number of households under poverty and the number of households for all inc ome levels.

3) Using sub-function $\mathbf{C 1 2}$ - Product to derive the measures of precision for the estimate of a total. The two estimates for the product are the average from 1 ) and the total frequency 
from 2). This step needs to be done for both households under poverty and all households.

4) Use sub-function C10 - Ratio to derive measures of precision for the percentage of vehic les available in households under poverty versus all households. The numerator would be the number of vehic les a vailable in households under poverty, and the denominator would be the number of vehic les a vailable in all households.

\section{Altemative Use}

Sub-functions C07 - Sum, C08 - Diff, and C10- Ratio may be used to derive mea sures of precision at an a ltemative confidence level for an estimate that a lrea dy has an MOE at a different confidence level. Sub-function A01 - ACS is designed to derive measures of precision for a $n$ a Itema tive confidence level, but it is limited to ACS estimates from published ta bles at Americ an FactFinder. For deriving measures of precision at a $n$ altema tive confidence level for other estima tes that already have an MOE and a different confidence level, users may do the following:

- $\quad$ 07 - Sum: Enter the required input data for a single estimate.

- $\mathbf{C 0 8}$ - Diff. Enter the required input data for the minuend but enter 0 for both the subtrahend and its MOE.

- C10-Ratio: Enter the required input data for the numerator but enter 1 for the denominator and 0 for its MOE. 
This page intentiona lly left blank. 


\section{DATA NEEDS}

The worksheet for each sub-function lists the data needs and how they should be entered in detail. These details are not repeated here. Instead, this section focuses on the following issues:

- Obta ining data from Americ an FactFinder.

- Obtaining data from the CTPP.

- Summary of data needs for Function B.

- Obta ining required data for Function B.

Unlike for other functions, the sub-functions of Function B require certain input data that a re unique to them. These unique data items require some explanation on what each required data item is and how it may be obtained.

\section{Obtaining Data from American FactFinder}

\section{Census 2000}

Americ an FactFinder provides Census 2000 estimates in published ta bles but no mea sure of precision. These estimates were derived from Census 2000 Summary File 3. The ACS Statistical Analyzer can be used to derive all mea sures of prec ision for these estimates.

All required input data from Census 2000 for using the ACS Statistic al Analyzer ca n be obta ined directly or indirectly through the Census Bureau's web page, as shown in Figure 1. Published tables and related technic al documentation a re located on the right-hand side once the appropriate summary file is chosen from the middle of the page. Most relevant for the ACS Statistical Analyzer would be Census 2000 Summa ry File 3. PUMS files and related technical documentation a re located at web pages accessible through the link at "Download data sets via FIP" located at the upper right-hand comer under "Other Resourc es."

\section{ACS}

Americ an FactFinder provides both estimates and their MOE at the $90 \%$ confidence level in published tables that a re derived from the full ACS sample. The ACS Statistical Ana lyzer can be used to derive other mea sures of precision for these estimates and all mea sures of precision for an a ltemative confidence level. American FactFinder also provides ACSPUMS data sets for users to derive estimates for geogra phic al a reas or population groups that a re not available in published ACS tables. The ACS Statistic al Analyzer can be used to derive all mea sures of precision for these PUMS estimates.

Users can easily obtain the required input data from the ACS at the Data Sets web page of the $A C S$, as shown in Figure 2. The middle of the page lists the available single-year a nd multi-year ACS datasets. Once a particular data set is selected, as illustrated in Figure 2 for the 2006-2008 three-year data set, the list of ava ila ble types of published ta bles of ACS estimates appea rs on the right-hand side. This list can vary a cross the different data sets, particularly between singleyearand multi-yeardatasets. Also shown in this list is a link to download the PUMS file for the 
selected ACS dataset. For deta ils about data productsfrom the ACSproduced by the U.S. Census Burea u, users are referred to the Quick Guide to the Americ an Community Survey (ACS) Products in Americ an FactFinder at http://factfind er.census.gov/home/saff/aff_acs2008_quic kguide.pdf.

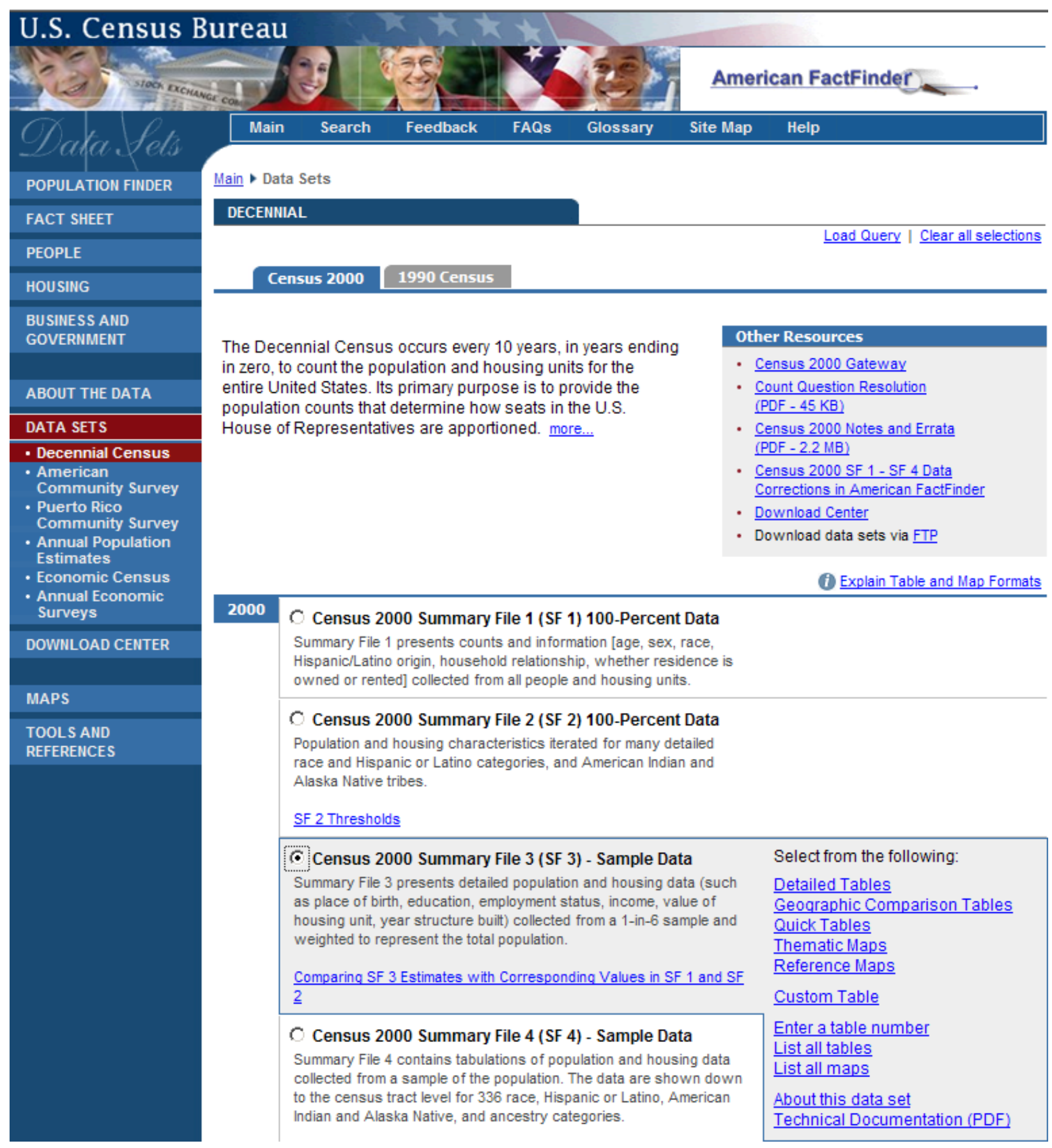

Figure 1. U.S. Census Bureau's Web Page for Census 2000 Information 


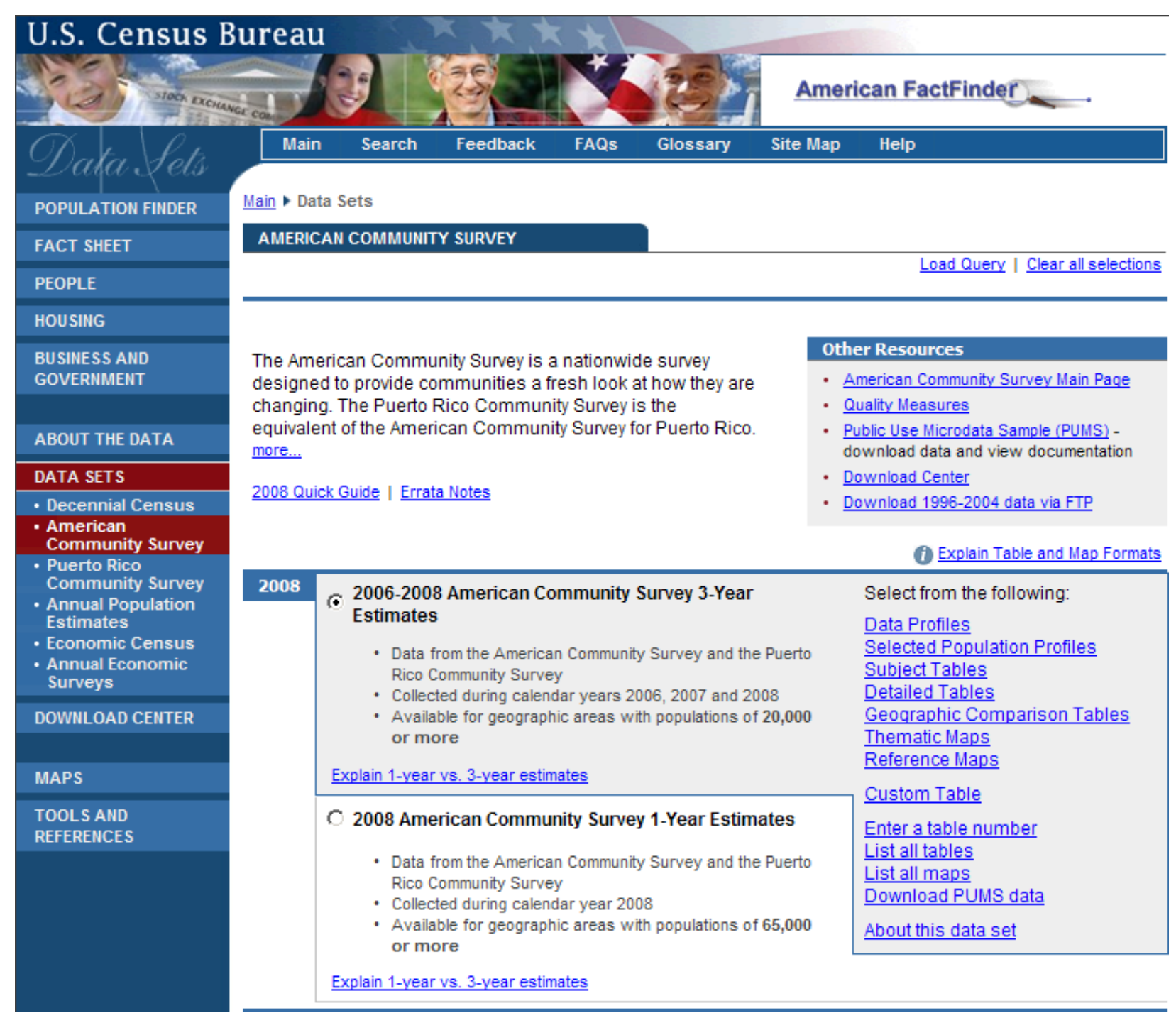

Figure 2. ACSWeb Page for Available Data Sets

\section{Obtaining Data from the CTPP}

Accessible at http://www.fhwa.dot.gov/ctpp/data prod.htm, the CTPP provides estima tes in three sets of pre-specified tables, including residence tables, place of work tables, and joumeyto-work flow tables, for both the ACS and Census 2000. Most of the estimates in the CTPP ACS tables come with their $90 \%$ MOE as well; their MOE information is not provided for some estimates, particularly for ratios and percentages. Estimates in the CTPP 2000 do not come with any mea sure of precision. The ACS Statistic al Analyzercan be used to derive mea sures of prec ision for estimates from the residence tables or joumey-to-work flow tables, but not from the place of work tables. 


\section{Summary of Data Needs for Function B}

The unique data requirements for Function B a re described. Table 1 lists each required data item and which sub-function uses it. Each of the first six data items is directly used in the ACS Statistical Analyzer. The last two data items are used only to define a design factor.

Table 1. Unique Data Requirements for Function B

\begin{tabular}{|c|c|c|c|c|c|}
\hline 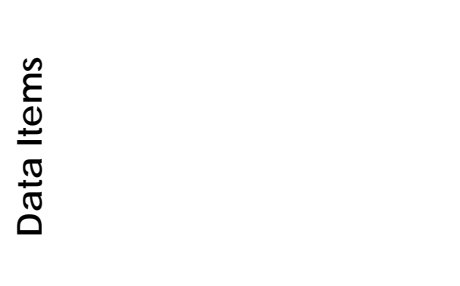 & 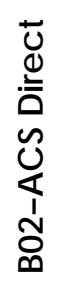 & 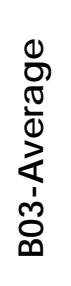 & $\begin{array}{l}\frac{c}{\sigma} \\
\frac{0}{8} \\
\sum_{0}^{0} \\
\frac{1}{8} \\
0\end{array}$ & 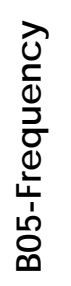 & 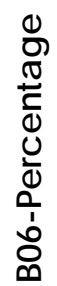 \\
\hline 1. Source of Data & & $X$ & $X$ & $X$ & $\mathrm{X}$ \\
\hline 2. Replicate Estimates & $\mathrm{X}$ & & & & \\
\hline 3. Size of the Geography & & & & $x$ & \\
\hline 4. Base of a Percentage & & & & & $\mathrm{X}$ \\
\hline 5. Distribution Table & & $\mathrm{X}$ & $\mathrm{X}$ & & \\
\hline 6. Design Factor & & $\mathrm{X}$ & $\mathrm{X}$ & $\mathrm{X}$ & $\mathrm{X}$ \\
\hline 7. Percent in Sample & & $\mathrm{X}$ & $\mathrm{X}$ & $x$ & $\mathrm{X}$ \\
\hline 8. State of the Geography & & $\mathrm{X}$ & $\mathrm{X}$ & $X$ & $\mathrm{X}$ \\
\hline
\end{tabular}

1. Source of Data refers to the original source for the other data items. There a re six original sources - the full 2000 long-form survey for published 2000 estimates, 1\% 2000 PUMS, 5\% 2000 PUMS, 1-year ACS, 3-year ACS, and 5-yearACS. The information on these sources determines the finite population correction factor. This correction factor is determined by the total number of housing units sampled as a percent of all housing units at the national level for each of these six sources. This correction factor is used by most of the sub-functions of Function B to derive precision measures.

While it is not necessary for the user to know the specific value of this correction factorfor each source, Table 2 shows the national sample size and the specific value of the finite population correction factorforeach source for those users who are interested in them.

Table 2. Finite Population Comection Factor by Data Source

\begin{tabular}{|l|c|c|}
\hline \multicolumn{1}{|c|}{ Source } & National Sample & $\begin{array}{c}\text { Finite Population } \\
\text { Comection Factor }\end{array}$ \\
\hline 2000 Long-Fom Survey & $16.67 \%$ & 5 \\
\hline $20001 \%$ PUMS & $1 \%$ & 99 \\
\hline 2000 5\% PUMS & $5 \%$ & 19 \\
\hline 1-Year ACS & $1 \%$ & 99 \\
\hline 3-YearACS & $3 \%$ & $97 / 3$ \\
\hline 5-YearACS & $5 \%$ & 19 \\
\hline
\end{tabular}


2. Replic ate Estimates a re supplemental estima tes to any ACS estimate that a user can obta in from an ACSPUMS. The ACS estimate and a total of 80 replic ate estimates can be used to determine the precision measures for the ACS estimate. Every ACSPUMS file comes with the full weight for obta ining the ACS estima te of interest. Every ACS PUMS file also comes with 80 sets of replicate weights for obtaining the replicate estimates:

- PWG TP1 through PWG TP80 should be used for characteristic s related to persons

- WG TP1 through WG TP80 should be used for characteristic s related to households, fa milies, or housing units

3. Size of the Geography refers to the total number of persons, households, families, or housing units in the geography for which the estimate of interest is measured. If the estimate is of the number of persons, use the number of total population; if the estimate is of families or households, use the number of households; otherwise, use the number of housing units.

4. Base of a Percentage refers to the denominator used in computing the percentage. If the percentage is the number of workers who usually commuted to work by public transportation as a percent of all workers during 2008 in Miami City, for example, the base would be the total number of workers during 2008 in Miami City. These estimates of perc entages may be directly obta ined from Americ an FactFinder, CTPP 2000, CTPP ACS, or derived by the user.

5. A Distribution Table shows the number of persons, workers, households, fa milies, or housing units by ranges of a characteristic on a numerical scale. Examples of characteristic s on a numeric al scale include inc ome, number of vehic les a vailable, age, travel time, etc. The specific distribution table to be used for a specific a nalysis depends on the specific average and median. For selection purposes, the foc us should be on the characteristic and whether the a vera ge or media $n$ is a bout persons, workers, households, families, or housing units:

- If the average of interest is a verage commuting time perworker, the distribution table should show the number of workers for each range of commuting time.

- If the median of interest is median household income, the distribution table should show the number of households foreach range of household income.

6. Design Factor refers to an adjustment factor by most of the sub-functions of Function B. For Census 2000, design factors vary by the state of the geography, by the characteristic for the estimate, and a percent in sample value. For the ACS, design factors vary by the state of the geography and by the characteristic for the estimate. A design factor reflects the effect of how the original survey data were collected and how the estimate of interest was derived.

If a n estimate is a combination of two or more characteristics, use the largest design factor for this combination of characteristics. The only exc eption to this is for items crossed with race or Hispanic Origin. For an item crossed with race or Hispanic Origin, use the largest design factor not including the race or Hispanic Origin design factor. 
7. A Percent in Sample value refers to the number of units in the sample as a percent of the total number of units in the geography of interest for the estimate in question. The units a re in terms of persons or housing units (including households or families). A percent in sample value is unique to both the geography and the characteristic for the estimate in question. There are two types of percent in sample values. The percent of the population in sample is used for selecting the design factorfor a population characteristic. The percent of the total housing units in sample is used for selecting the design factor for a housing characteristic. It is relevant to design factors for Census 2000.

8. State of the Geography refers to the state in which the geography of the estimate of interest is located. If the user is interested in the share of workers who usually commuted to work by public transportation during 2008 in Miami City, for example, the state of the geography would be Florida. If the geography for the estimate of interest covers more than one state, the state of the geography would be the United States. This information is used in selecting the design factor, and design factors a re available for the United States as a whole as well as for ind ividual states.

\section{Obtaining Required Data for Function B}

A user's interest in a partic ula restima te of a characteristic determines the required source of data and the state of the geography for the estimate. A user derives replic a te estimates from an ACSPUMS rather tha $n$ obta ining them directly from Americ a $n$ FactFinder. The following describes how each of the other required data items for Function $B$ may be obta ined from Americ an FactFinder.

\section{Size of the Geography}

The size of the geography for a given characteristic (i.e., persons, households, etc.) is ava ila ble in many of the "Detailed Tables" at American FactFinder for both Census 2000 and the ACS. Table 3 suggests a set of these possible tables and the actual sizes for Miami City:

Table 3. American FactFinder "Detailed Tables" for Size of the Geography

\begin{tabular}{|c|c|l|c|c|}
\hline Source & Table & \multicolumn{1}{|c|}{ Description } & $\begin{array}{c}\text { Measure of } \\
\text { Size }\end{array}$ & $\begin{array}{c}\text { Size (Miami } \\
\text { City, Rorida) }\end{array}$ \\
\hline \multirow{4}{*}{$\begin{array}{c}\text { ACS } \\
\text { (2008) }\end{array}$} & B01003 & Total Population & Persons & 343,142 \\
\cline { 2 - 5 } & B11012 & Household Type by Tenure & Households & 138,786 \\
\cline { 2 - 5 } & B25001 & $\begin{array}{l}\text { Fa mily Type by Presence a nd Age of Own } \\
\text { Child ren under 18 Years }\end{array}$ & Fa milies & 77,218 \\
\hline \multirow{3}{*}{$\begin{array}{c}\text { Census } \\
2000\end{array}$} & P1 & Total Population & Housing Units & 168,252 \\
\cline { 2 - 5 } & P10 & $\begin{array}{l}\text { Household Size by Household Type by } \\
\text { Presence Of Own Children under 18 Years }\end{array}$ & $\begin{array}{l}\text { Fouseholds } \\
\text { under 18 Years by Age of Own Children }\end{array}$ & 134,344 \\
\cline { 2 - 5 } & H1 & Housing Units & Families & 84,195 \\
\hline
\end{tabular}




\section{Base of a Percentage}

An example is used to illustrate obtaining data for the base of a percentage. The percentage of interest is the percent of workers in Mia mi City who usually carpooled to work in 2000 . The base of the percentage depends on whether workers who worked at home were included as a mode of commuting in computing the percentage. If working at home is included as a mode, the base would be the total number of workers. If working at home is not included as a mode, the base would be the total number of workers minus the number of workers who worked at home.

Figure 3 shows Detailed Table QT-P23 from Census 2000 Summary File 3. The base of this percentage is 126,536 if this percentage is computed with working at home as a mode, but is 123,931 if working at home is not included as a mode.

\section{Distribution Table}

The specific distribution table to be used for a specific a nalysis depends on the specific average ormedian. For selection purposes, the foc us should be on the characteristic and whether the a verage or median is a bout persons, workers, households, fa milies, or housing units. Two examples a re considered.

Example 1. According to Detailed Table P53, Median Household Income in1999 (dollars), for Census 2000 Summary File 3 (SF 3), the median household inc ome in Mia mi City was $\$ 23,483$ in 1999. In this example, the metric is household income, and the median relates to households. As a result, the distribution table should show the number of households by ranges of household income. Detailed Table P52, MEDIAN HOUSEHOLD INCOME IN 1999 (DOWARS), is such a ta ble for Mia mi City:

Table 4. A Distribution Table of Household Income, Miami, Ronida

\begin{tabular}{|l|c|}
\hline Range of Household Inc ome & Households \\
\hline Less tha $\$ 10,000$ & 32,558 \\
\hline$\$ 10,000$ to $\$ 14,999$ & 14,370 \\
\hline$\$ 15,000$ to $\$ 19,999$ & 12,080 \\
\hline$\$ 20,000$ to $\$ 24,999$ & 11,007 \\
\hline$\$ 25,000$ to $\$ 29,999$ & 9,128 \\
\hline$\$ 30,000$ to $\$ 34,999$ & 8,152 \\
\hline$\$ 35,000$ to $\$ 39,999$ & 6,763 \\
\hline$\$ 40,000$ to $\$ 44,999$ & 5,737 \\
\hline$\$ 45,000$ to $\$ 49,999$ & 4,536 \\
\hline$\$ 50,000$ to $\$ 59,999$ & 7,360 \\
\hline$\$ 60,000$ to $\$ 74,999$ & 7,124 \\
\hline$\$ 75,000$ to $\$ 99,999$ & 6,458 \\
\hline$\$ 100,000$ to $\$ 124,999$ & 3,319 \\
\hline$\$ 125,000$ to $\$ 149,999$ & 1,510 \\
\hline$\$ 150,000$ to $\$ 199,999$ & 1,581 \\
\hline$\$ 200,000$ or more & 2,661 \\
\hline
\end{tabular}




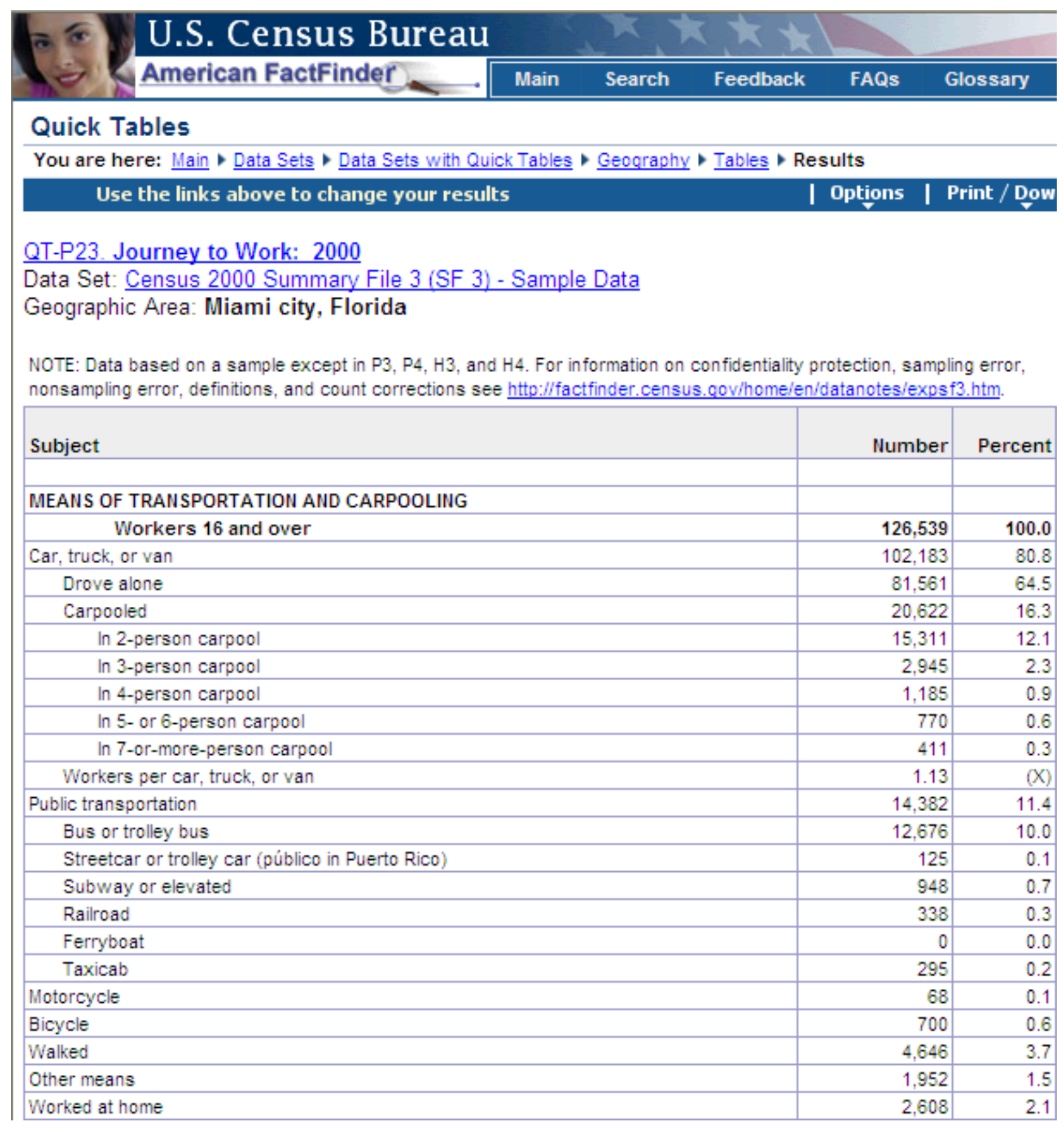

Figure 3. An Example of the Base of a Percentage

Example 2. This example illustrates the selection of a distribution table for deriving measures of precision for workers' avera ge travel time to work. "Deta iled Tables" for Census 2000 Summary File 3 do not have any published table that shows average travel time to work. However, Quick Table QT-P23 shows 28.1 minutes as the average travel time to work for Miami City. In this case, the metric is travel time to work and the average is about workers. Asa result, we need a distribution table that shows the number of workers who did not work at home by ranges of travel time to work. 
Detailed Table P31 has information for such a distribution table. Table 5 shows the information from Detailed Table P31 for Miami City. Only the rows in italic would be the distribution table to derive measures of precision for the average travel time to work.

Table 5. Detailed Table P31, Miami City, Forida

\begin{tabular}{|c|r|}
\hline Range of Travel Time & Workers \\
\hline Total: & 126,539 \\
\hline Did not work at home & 123,931 \\
\hline Less than 5 minutes & 1,832 \\
\hline 5 to 9 minutes & 8,094 \\
\hline 10 to 14 minutes & 14,858 \\
\hline 15 to 19 minutes & 21,137 \\
\hline 20 to 24 minutes & 20,206 \\
\hline 25 to 29 minutes & 6,890 \\
\hline 30 to 34 minutes & 24,268 \\
\hline 35 to 39 minutes & 2,428 \\
\hline 40 to 44 minutes & 4,059 \\
\hline 45 to 59 minutes & 8,211 \\
\hline 60 to 89 minutes & 7,703 \\
\hline 90 or more minutes & 4,245 \\
\hline Worked at home & 2,608 \\
\hline
\end{tabular}

\section{Percent in Sample}

Table 6 shows the location of these percent-in-sample values for Census 2000 at American FactFinder and actual values for Miami City.

Table 6. American FactFinder "Detailed Tables" for Percent in Sample Values

\begin{tabular}{|c|l|c|c|}
\hline Table & \multicolumn{1}{|c|}{ Description } & $\begin{array}{c}\text { Type of } \\
\text { Characteristics }\end{array}$ & $\begin{array}{c}\text { Miami City, } \\
\text { Fonida }\end{array}$ \\
\hline P4 & PERCENTOF THE POPULATION IN SAMPLE & Population & 12.0 \\
\hline H4 & $\begin{array}{l}\text { PERCENTOF HOUSING UNITS IN SAMPLE } \\
\text { BY OCCUPANCY STATUS }\end{array}$ & Occupied Housing & 12.3 \\
\hline
\end{tabular}

\section{Design Factors}

The design factors for Census 2000 are in Ta ble C, Chapter 8 of Census 2000 Summary File 3 Technic al Doc umentation at http://www.census.gov/prod/cen2000/doc/sf3.pdf. This PDF document also can be accessed by clicking "Technic al Doc umentation (PDF)" located at the lower right-hand comer of Figure 1. Once this PDF file is open, these tables a re assessable via its bookmarks. Since this set of design factors will not change in the future, they have been included in a worksheet, $\mathbf{2 0 0 0}$ DF, of the ACS Statistic al Ana lyzer for ea sy a c cess by the user. 
The design factors for an ACS PUMS, however, need to be obtained from American FactFinder. These are conta ined in the PUMS Accuracy of the Data report. This report may be obta ined by clic king "Public Use Micro Data Sample (PUMS)" loc ated at the upper right-hand comer of Figure 2. These design factors for up to 2008 were calculated using 2005 ACS data. They may change, however, for future PUMS data and will be updated periodic ally. 


\section{REFRENCES}

These references may not be directly cited in this doc ument, but information from them was used in developing the ACS Statistic al Analyzer and this doc ument.

Gaines, Leonard, ACSAdvanced Applic ations and Issues, Technic al Append ix to the ACS User Handbook, unpublished draft, not dated.

(https://c tools.umic h.edu/a c c ess/c ontent/group/34a 72eab-da a 4-4d 14-80e0-

9150727a ed6c/Technic a I\%20-\%20Statistical/ AC S\%20Technic al\%20Appendices_Gaines.pdf).

U.S. Census Bureau, PUMS Acc uracy of the Data (2008), Section 6.1, not dated. http://www.census.gov/acs/www/Downloads/2008/Acc ura c yPUMS.pdf.

U.S. Census Bureau, Census 2000, Public Use Microdata Sample, (PUMS), United States, Technic al Doc umentation, Chapter 4 - Accuracy of the Mic rodata Sample Estimates, U.S. Govemment Printing Office, Washington, D.C., 2003.

U.S. Census Burea u, Census 2000 Summa ry File 3 Tec hnic al Doc umentation, Cha pter 8 Accuracy of the Data and Chapter 9 - Tec hnic al Documentation Notes, U.S. Govemment Printing Office, Wa shington, DC, 2007. (http://www.census.gov/prod/cen2000/doc/sf3.pdf)

U.S. Census Burea u, A Compass for Understanding and Using Americ a n Community Survey Data: What Researchers Need to Know, Append ix 3, U.S. Govemment Printing Office, Washington, DC, 2009. (www.census.gov/acs/www/Downloads/ACSResearch.pdf) 
This page intentiona lly left blank. 


\section{APPENDIX}

This appendix provides the statistical procedures and formulas involved in the calculations for each of the 15 sub-functions of the ACS Statistical Analyzer. The steps, symbols, formulas, and related descriptions for each sub-function are adopted from the references.

\section{Function A}

A01 - ACS derives other precision measures for individual published ACS estimates that already have an MOE at the $90 \%$ confidence level. This function derives an estimate's relative reliability and its confidence interval at the current confidence level. At an alternative confidence level, this function also derives a new MOE and a new confidence interval. These calculations require deriving the standard error of an estimate from its MOE.

\section{Deriving the Standard Error from the MOE}

For an MOE at a given confidence level $\alpha$, the associated standard error is expressed as:

$$
\text { Standard Error }=\frac{\mathrm{MOE}_{\alpha}}{\mathrm{M}_{\alpha}}
$$

In this formula $M_{\alpha}$ is the confidence multiplier, which is 1.645 for the $90 \%$ confidence level, 1.96 for the $95 \%$ confidence level, and 2.576 for the $99 \%$ confidence level. If working with published ACS 1-year estimates for 2005 or earlier, use the value 1.65 rather than 1.645 as the confidence multiplier.

\section{Deriving the Relative Reliability}

The relative reliability is traditionally called the coefficient of variation for an estimate. It is given by the ratio of the estimate's standard error over the estimate. It is stated in percent terms. Specifically, the relative reliability of an estimate is:

$$
\text { Relative Reliability }=\frac{\mathrm{SE}}{\mathrm{X}} \cdot 100
$$

where $\mathrm{X}$ is the estimate and SE is its standard error.

\section{Deriving the Confidence Interval from the MOE}

For an estimate $\mathrm{X}$ and its MOE at a given confidence level $\alpha$, the lower and upper bounds of its confidence interval at the same confidence level are given by:

$$
\begin{gathered}
\mathrm{L}_{\alpha}=\mathrm{X}-\mathrm{MOE}_{\alpha} \\
\mathrm{U}_{\alpha}=\mathrm{X}+\mathrm{MOE}_{\alpha}
\end{gathered}
$$

Users should consider logical boundaries when creating confidence intervals from an estimate's MOE:

- The lower boundary may be less than zero as calculated above for an estimate that is small; a negative number does not make sense in most cases of using ACS and Census 2000 data. So the 
lower boundary should be set to zero. One exception to this consideration would be a confidence interval for an estimate of a difference between two existing estimates.

- The upper boundary may be greater than $100 \%$ as calculated using the formulas above for an estimate of a percentage that is close to $100 \%$. A percentage greater than $100 \%$ does not make sense; so the upper bound in this case should be set to $100 \%$.

\section{Deriving the MOE for an Alternative Confidence Level}

For an $\mathrm{MOE}_{\alpha}$ at a given confidence level $\alpha$, the $\mathrm{MOE}_{\beta}$ at an alternative confidence level $\beta$ can be expressed as:

$$
\mathrm{MOE}_{\beta}=\frac{\mathrm{M}_{\beta}}{\mathrm{M}_{\alpha}} \cdot \mathrm{MOE}_{\alpha}
$$

In this formula, $\mathrm{M}_{\alpha}$ and $\mathrm{M}_{\beta}$ are the confidence multipliers for confidence levels $\alpha$ and $\beta$, respectively. If working with published ACS 1-year estimates for 2005 or earlier for the base MOE, use the value 1.65 rather than 1.645 for the confidence multiplier.

\section{Reference}

These procedures are from the following document:

U.S. Census Bureau, A Compass for Understanding and Using American Community Survey Data: What Researchers Need to Know, Appendix 3, pp. A-12, A-13, U.S. Government Printing Office, Washington, DC, 2009. (www.census.gov/acs/www/Downloads/ACSResearch.pdf)

\section{Function B}

\section{B02 - ACS Direct}

This sub-function derives measures of precision for frequencies, totals, averages, or medians from an ACS PUMS using replicate estimates. Replicate estimates can be used to calculate what is referred to as direct standard errors. Standard errors for the published ACS estimates are calculated using replicate estimates. Direct standard errors will often be more accurate than those standard errors derived from the other subfunctions of Function B. The advantage of using replicate estimates is that a single formula is used to calculate the standard error of many forms of estimates.

Each housing unit and person record contains a full weight and 80 replicate weights. The full weight is used to derive the estimate of interest $\mathrm{X}$. For this discussion, $\mathrm{X}$ is referred to as the full sample estimate. The 80 replicate weights are used to derive 80 replicate estimates. The first replicate estimate $X_{1}$ is computed using the first replicate weight, the second replicate estimate $\mathrm{X}_{2}$ is computed using the second replicate weight, and so on. Each replicate estimate is computed using the replicate weights in the same way that the full sample estimate $\mathrm{X}$ is computed.

The standard error of $\mathrm{X}$ is estimated using the sum of the squared differences between each replicate estimate $\mathrm{X}_{\mathrm{r}}$ and the full sample estimate $\mathrm{X}$. The standard error formula is:

$$
\mathrm{SE}(\mathrm{X})=\sqrt{\frac{4}{80} \sum_{\mathrm{r}=1}^{80}\left(X_{\mathrm{r}}-\mathrm{X}\right)^{2}}
$$


This formula fails to provide correct measures of precision for the following conditions:

- The estimate of $\mathrm{X}$ is zero

- The estimated MOE for a median is zero

- The estimate of a frequency is controlled at some aggregate level, such as total male or total female persons living in households in a state

Switch to using the other sub-functions of Function B in these cases:

- B03 - Average if the estimate of interest is an average

- B04 - Median if the estimate of interest is a median.

- B05 - Frequency if the estimate of interest is a frequency.

These procedures are from the following:

U.S. Census Bureau, PUMS Accuracy of the Data (2008), Section 6.1, not dated. http://www.census.gov/acs/www/Downloads/2008/AccuracyPUMS.pdf.

\section{B03 - Average}

This sub-function derives measures of precision for averages using a distribution table. The formula for estimating the standard error of an average, $x$, is

$$
\mathrm{SE}(\mathrm{x})=\sqrt{\left(\frac{\mathrm{f}}{\mathrm{base}} \cdot \mathrm{s}^{2}\right)} \cdot \text { Design Factor }
$$

In this equation, $\mathrm{f}$ is the finite population correction factor, the base is the sum of the frequencies in the distribution table, and $\mathrm{s}^{2}$ may be estimated using data in the distribution table. Use Table 2 in the section on data needs and the source of data for the distribution table to determine the finite population correction factor.

For this method, the value for the characteristic is divided into c ranges, where the lower and upper boundaries of range $\mathrm{j}$ are $\mathrm{L}_{\mathrm{j}}$ and $\mathrm{U}_{\mathrm{j}}$, respectively. Each unit is placed into one of the $c$ ranges such that the value of the characteristic is between $L_{j}$ and $U_{j}$. The estimated $s^{2}$ is then given by:

$$
s^{2}=\sum_{j=1}^{c} p_{j} m_{j}^{2}-x^{2}
$$

where $\mathrm{p}_{\mathrm{j}}$ is the estimated proportion of units in range $\mathrm{j}$ (based on weighted data) and $\mathrm{m}_{\mathrm{j}}$ is the midpoint of the $\mathrm{j}^{\text {th }}$ range, calculated as:

$$
m_{j}=\frac{L_{j}+U_{j}}{2}
$$

If the $\mathrm{c}^{\text {th }}$ range is open-ended, (i.e., no upper range boundary exists) then approximate $\mathrm{m}_{\mathrm{c}}$ by: 


$$
\mathrm{m}_{\mathrm{c}}=\left(\frac{3}{2}\right) \mathrm{L}_{\mathrm{c}}
$$

The above procedures are applicable to both Census 2000 and ACS PUMS data. For Census 2000 data, they are the recommended method by the U.S. Census Bureau in the following document:

U.S. Census Bureau, Census 2000, Public Use Microdata Sample, (PUMS), United States, Technical Documentation, Chapter 4 - Accuracy of the Microdata Sample Estimates, p. 4-6, U.S. Government Printing Office, Washington, D.C., 2003.

For ACS PUMS data, these procedures will give an approximation for the measures of precision of an average. The U.S. Census Bureau, however, has recommended a different method to approximate the measures of precision for an average. For 2004 or earlier ACS data, the recommended method is in the following document:

U.S. Census Bureau, PUMS Accuracy of the Data (2004). http://www.census.gov/acs/www/Downloads/2004/AccuracyPUMS.pdf.

For 2005 or later ACS data, the recommended method is in the following document:

U.S. Census Bureau, PUMS Accuracy of the Data (2008), Section 6.1, not dated. http://www.census.gov/acs/www/Downloads/2008/AccuracyPUMS.pdf.

The Census-recommended method for 2005 or later ACS data requires data at the individual household level and is not included in the current tool. If users want exact measures of precision of an average, they should use sub-function B02 - ACS Direct.

\section{B04 - Median}

This sub-function derives measures of precision for medians using a distribution table. It involves the following steps:

1. From Table 2 determine the finite population correction factor $\mathrm{f}$.

2. Obtain the appropriate (person or housing unit) observed percent in sample value for the specific geographic area. Use this value to locate the design factor for the characteristic of interest.

3. Obtain the distribution table for the selected variable. Cumulate these frequencies to yield the base.

4. Determine the standard error of the estimate of 50 percent from the distribution using the formula:

$$
\mathrm{SE}(50 \text { percent })=\sqrt{\left(\frac{\mathrm{f}}{\mathrm{base}} \cdot 50^{2}\right)} \cdot \text { Design Factor }
$$

5. Subtract from and add to 50 percent the standard error determined in step 4 .

$$
\begin{gathered}
\text { p_lower }=50-\operatorname{SE}(50 \text { percent }) \\
\text { p_upper }=50+\operatorname{SE}(50 \text { percent })
\end{gathered}
$$


6. Determine the range in the distribution table containing p_lower and the range in the distribution table containing p_upper. If p_lower and p_upper fall in the same range, follow the steps below. If p_lower and p_upper fall in different ranges, go to step 9.

- Define A1 as the smallest value in that range.

- Define A2 to be the smallest value in the next (higher) range.

- Define $\mathrm{C} 1$ as the cumulative percent of units strictly less than A1.

- $\quad$ Define C2 as the cumulative percent of units strictly less than A2.

7. Use the following formulas with p_lower, p_upper, A1, A2, C1, and C2 to determine a lower bound and an upper bound:

$$
\begin{aligned}
& \text { Lower Bound }=\left[\frac{\text { p_lower }-\mathrm{C} 1}{\mathrm{C} 2-\mathrm{C} 1}\right] \cdot(\mathrm{A} 2-\mathrm{A} 1)+\mathrm{A} 1 \\
& \text { Upper Bound }=\left[\frac{\mathrm{p} \_ \text {upper }-\mathrm{C} 1}{\mathrm{C} 2-\mathrm{C} 1}\right] \cdot(\mathrm{A} 2-\mathrm{A} 1)+\mathrm{A} 1
\end{aligned}
$$

8. Divide the difference between the lower and upper bounds, determined in step 7 above, by two to obtain the estimated standard error of the median:

$$
\mathrm{SE}(\text { median })=\frac{\text { Upper Bound }- \text { Lower Bound }}{2}
$$

9. For the range:

a. containing p_lower, define the values A1, A2, C1, and C2 as described in step 6 above. Use these values and the formula in step 7 to obtain the Lower Bound.

b. containing p_upper, define a new set of values for $\mathrm{A} 1, \mathrm{~A} 2, \mathrm{C} 1$, and $\mathrm{C} 2$ as described in step 6 . Use these values and the formula in step 7 to obtain the Upper Bound.

10. Use the Lower Bound and Upper Bound obtained in step 8 and the formula in step 7 to calculate the standard error of the estimated median.

The above procedures are from the following:

U.S. Census Bureau, Census 2000, Public Use Microdata Sample, (PUMS), United States, Technical Documentation, Chapter 4 - Accuracy of the Microdata Sample Estimates, pp. 4-4, 4-5, U.S. Government Printing Office, Washington, D.C., 2003.

\section{B05 - Frequency}

This sub-function derives measures of precision for frequencies from Census 2000 or a PUMS using design factors. The formula for calculating the standard error for an estimate of a frequency is given by:

$$
\mathrm{SE}(\mathrm{Y})=\sqrt{\left[\mathrm{f} \cdot \mathrm{Y}\left(1-\frac{\mathrm{Y}}{\mathrm{N}}\right)\right]} \cdot \text { Design Factor }
$$

In this formula, $\mathrm{f}$ is the finite population correction factor, $\mathrm{Y}$ is the estimate of a frequency, and $\mathrm{N}$ is the size of the geography in the same unit as the estimate of the frequency. If an estimated frequency is less than 425 or 
within 425 of the total size of the tabulation area, use a basic standard error of 246 multiplied by the design factor for the estimate.

The above procedures are from the following:

U.S. Census Bureau, Census 2000, Public Use Microdata Sample, (PUMS), United States, Technical Documentation, Chapter 4 - Accuracy of the Microdata Sample Estimates, p. 4-8, U.S. Government Printing Office, Washington, D.C., 2003.

While this document or any other document from the U.S. Census Bureau containing this formula does not explicitly make it clear, this formula applies to estimates of the number of persons, households, families, or housing units only. It does not apply to estimates of totals such as total household income, total commuting time by workers, total number of available household vehicles, total rent, etc. in a geographic area.

\section{B06 - Percentage}

This sub-function derives measures of precision for frequency-based percentages using design factors. The formula for calculating the standard error for an estimate of a frequency-based percentage is given by:

$$
S E(p)=\sqrt{\left[\frac{f}{B} \cdot p(1-p)\right]} \cdot \text { Design Factor }
$$

In this formula, $\mathrm{f}$ is the finite population correction factor, $\mathrm{p}$ is the estimate of a percentage, and $\mathrm{B}$ is the base of the percentage. If an estimate of a percentage is smaller than $2 \%$ (greater than $98 \%$ ), the value of $2 \%$ $(98 \%)$ is used when using this formula.

The above procedures are from the following:

U.S. Census Bureau, Census 2000, Public Use Microdata Sample, (PUMS), United States, Technical Documentation, Chapter 4 - Accuracy of the Microdata Sample Estimates, p. 4-9, U.S. Government Printing Office, Washington, D.C., 2003.

While this document or any other document from the U.S. Census Bureau containing this formula does not explicitly make it clear, this formula applies to estimates of percentages derived from estimates of frequencies such as persons, households, families, or housing units only. The percentage of workers who usually commuted to work by bus in a state would be an example. It does not apply to estimates of percentages that are derived in terms of totals such as total household income, total commuting time by workers, total number of vehicles available, total rent, etc. in a geographic area. The percentage of vehicles available in households under poverty versus all households in an area would be an example of these percentages.

\section{Function C}

This function derives new estimates and their precision measures from two or more original estimates that already have an MOE. These new estimates may be derived from one of the following six operations:

C07 - Sum derives the sum of two or more estimates and its measures of precision. The MOE for a sum is calculated as: 


$$
\mathrm{MOE}_{\text {sum }}=\sqrt{\sum_{\mathrm{c}} \mathrm{MOE}_{\mathrm{c}}^{2}}
$$

where $\mathrm{MOE}_{\mathrm{c}}$ is the MOE of component estimate $\mathrm{c}$.

C08 - Diff derives the difference of two estimates and its measures of precision. The procedure to calculate the MOE of a sum discussed previously should be used here to obtain the MOE of a difference.

C09 - \%Diff derives the percent difference of two estimates and its measures of precision. The procedure to calculate the MOE of a ratio discussed next should be used to obtain the MOE of the percent difference.

C10 - Ratio derives a ratio from two estimates and its measures of precision with the numerator not being part of the denominator. The MOE for a ratio is calculated as:

$$
\mathrm{MOE}_{\text {ratio }}=\frac{\sqrt{\mathrm{MOE}_{\mathrm{num}}^{2}+\left(\mathrm{R}^{2} \cdot \mathrm{MOE}_{\mathrm{den}}^{2}\right)}}{\mathrm{X}_{\mathrm{den}}}
$$

where:

$\mathrm{MOE}_{\text {num }}$ of the MOE of the numerator.

$\mathrm{MOE}_{\mathrm{den}}$ is the MOE of the denominator.

$\mathrm{R}=\mathrm{X}_{\text {num }} / \mathrm{X}_{\mathrm{den}}$ is the derived ratio.

$\mathrm{X}_{\text {num }}$ is the estimate used as the numerator of the derived ratio.

$\mathrm{X}_{\mathrm{den}}$ is the estimate used as the denominator of the derived ratio.

C11 - Percentage derives a percentage from two estimates and its measures of precision with the numerator being part of the denominator. The MOE for a derived percentage is calculated as:

$$
\mathrm{MOE}_{\text {percentage }}=\frac{\sqrt{\mathrm{MOE}_{\mathrm{num}}^{2}-\left(\mathrm{p}^{2} \cdot \mathrm{MOE}_{\mathrm{den}}^{2}\right)}}{\mathrm{X}_{\mathrm{den}}}
$$

where:

$\mathrm{MOE}_{\text {num }}$ of the MOE of the numerator.

$\mathrm{MOE}_{\text {den }}$ is the MOE of the denominator.

$\mathrm{p}=\mathrm{X}_{\mathrm{num}} / \mathrm{X}_{\mathrm{den}}$ is the derived percentage.

$\mathrm{X}_{\text {num }}$ is the estimate used as the numerator of the derived percentage.

$\mathrm{X}_{\mathrm{den}}$ is the estimate used as the denominator of the derived percentage.

There are rare instances where the value under the square root will be negative. If that happens, use the formula for derived ratios which will provide a conservative estimate of the MOE.

C12 - Product derives the product of two estimates and its measures of precision. The MOE for a product is calculated as:

$$
\mathrm{MOE}_{\text {product }}=\sqrt{\left(\mathrm{A}^{2} \cdot \mathrm{MOE}_{\mathrm{B}}^{2}\right)+\left(\mathrm{B}^{2} \cdot \mathrm{MOE}_{\mathrm{A}}^{2}\right)}
$$


where $\mathrm{A}$ and $\mathrm{B}$ are the first and second estimates, respectively, $\mathrm{MOE}_{\mathrm{A}}$ is the $\mathrm{MOE}$ of the first estimate, and $\mathrm{MOE}_{\mathrm{B}}$ is the MOE of the second estimate.

These procedures and formulas are from the following:

U.S. Census Bureau, A Compass for Understanding and Using American Community Survey Data: What Researchers Need to Know, Appendix 3, pp. A-14 through A-17, U.S. Government Printing Office, Washington, DC, 2009. (www.census.gov/acs/www/Downloads/ACSResearch.pdf)

\section{Function D}

Function D compares pairs of two estimates that already have an MOE. There are three sub-functions:

- One ACS estimate with another (D13 - ACS\&ACS)

- One ACS estimate with a Census 2000 estimate using an actual MOE for the 2000 estimate (D14 ACS\&2000 Actual)

- One ACS estimate with a Census 2000 estimate assuming the MOE for the Census 2000 estimate = the MOE for the ACS estimate (D15 - ACS\&2000 Assumed). This sub-function assumes that the MOE for a Census 2000 estimate is smaller than the ACS estimate. This assumption may be violated for some cases, such as controlled population.

For all three sub-functions, the test of significance can be expressed as follows. If the following is true

$$
\left|\frac{\mathrm{X}_{1}-\mathrm{X}_{2}}{\sqrt{\mathrm{SE}_{1}^{2}+\mathrm{SE}_{2}^{2}}}\right|>\mathrm{Z}_{\mathrm{CL}}
$$

then the difference between estimates $X_{1}$ and $X_{2}$ is statistically significant at the specified confidence level, CL. In the above equation:

- $X_{\mathrm{i}}$ is estimate $\mathrm{i}(=1,2)$

- $\mathrm{SE}_{\mathrm{i}}$ is the standard error for estimate $\mathrm{i}(=1,2)$

- $\mathrm{Z}_{\mathrm{CL}}$ is the critical value for the desired confidence level (=1.645 for 90 percent, 1.960 for 95 percent, 2.576 for 99 percent).

These procedures are from the following:

U.S. Census Bureau, A Compass for Understanding and Using American Community Survey Data: What Researchers Need to Know, Appendix 3, pp. A-18, U.S. Government Printing Office, Washington, DC, 2009. (www.census.gov/acs/www/Downloads/ACSResearch.pdf) 